\title{
Surface Magnetic Properties and Mössbauer Spectroscopy of As-Quenched FeNiMoCuB Ribbons
}

\author{
Ondrej Životský ${ }^{1}$, Yvonna Jirásková ${ }^{2}$, Kamila Hrabovská ${ }^{1}$, Jaromir Pištora ${ }^{1}$, and Valdirene Gonzaga de Resende ${ }^{3}$ \\ ${ }^{1}$ Department of Physics, Technical University of Ostrava, Ostrava, CZ70833, Czech Republic \\ ${ }^{2}$ Institute of Physics of Materials, Academy of Sciences of the Czech Republic, Brno, CZ 61662, Czech Republic \\ ${ }^{3}$ Dept. Subatomic and Radiation Physics, Ghent University, Gent, B 9000, Belgium
}

\begin{abstract}
Combination of surface-sensitive magneto-optical Kerr effect (MOKE) methods with the Conversion Electron and the Integral LowEnergy Electron Mössbauer spectroscopy (CEMS, ILEEMS), and with the X-ray diffraction (XRD) is used for structural investigation of the near-surface regions of as-prepared $\mathrm{Fe}_{40} \mathrm{Ni}_{36} \mathrm{Mo}_{8} \mathrm{Cu}_{1} \mathrm{~B}_{15}$ ribbons. Jumps observed at measured MOKE hysteresis loops indicate the presence of two magnetically different phases at both ribbon sides and enable to determine corresponding surface coercive fields. The grazing incidence XRD (GIXRD) results yield an existence of the crystalline $\mathrm{FeMo}_{2} \mathrm{~B}_{2}, \mathrm{FeNi}$ and amorphous phases confirmed by both surface-sensitive Mössbauer spectroscopy methods.
\end{abstract}

Index Terms-Amorphous materials, magnetic domains, magnetooptic Kerr effect, Mössbauer spectroscopy, X-ray scattering.

\section{INTRODUCTION}

$\mathbf{T}$ HE nanoperm-type Fe-M-B alloys, where $\mathrm{M}$ is an early transition metal such as $\mathrm{Zr}$, Nb, Mo etc., are extensively studied in amorphous and nanocrystalline states because of their excellent soft magnetic and mechanical properties. Recently, many papers are devoted to FeMoCuB systems [1]-[3] due to potential applications as magnetocaloric materials. It was shown that addition of $\mathrm{Cu}$ as nanocrystal-refining element and $\mathrm{Mo}$ as paramagnetic element significantly reduce the value of Curie temperature $\left(T_{\mathrm{c}}\right)$, while the crystallization temperature $\left(T_{\mathrm{cr}}\right)$ increases. Moreover, both $T_{\mathrm{c}}$ and $T_{\mathrm{cr}}$ parameters can be tuned by proper $\mathrm{Fe}$ to $\mathrm{B}$ ratio and in this way optimize the magnitude of magnetocaloric effect at room and higher temperatures.

The near-surface region of $\mathrm{FeMoCuB}$ ribbons was investigated with the emphasis on the nanocrystallization process and roughness of the surface layers [4], [5]. Depending on the conditions of the planar flow casting process either one side or both sides of ribbon in as-quenched state exhibit the presence of the surface crystalline phase penetrating a few hundred nanometers into the ribbon depth, while the remainder is fully amorphous. Quality of the surface of the quenching wheel, not ideally controllable conditions of preparation process and the insufficient quenching rates are considered to be the main sources of the surface irregularities. However, the origin of "air pockets" during preparation increases the roughness of the side in direct contact with quenching wheel (wheel side) in comparison to the opposite (air) side. The measured root mean square values are in the range from tenths to units of micrometers.

The present work is devoted to the magnetic properties of newly developed alloys, where $36 \%$ of $\mathrm{Fe}$ amount in the original $\mathrm{Fe}_{76} \mathrm{Mo}_{8} \mathrm{Cu}_{1} \mathrm{~B}_{15}$ system is substituted by Ni. Attempts to implement the nickel into the FINEMET and NANOPERM materials have shown an increase of $T_{\mathrm{c}}$ and $T_{\mathrm{cr}}$ connected with magnetic hardening in as-cast amorphous samples. Additional annealing at temperatures around $T_{\text {cr }}$ causes the decrease of

Manuscript received June 19, 2009; revised September 03, 2009; accepted September 21, 2009. Current version published January 20, 2010. Corresponding author: O. Životský (e-mail: ondrej.zivotsky@ post.cz).

Digital Object Identifier 10.1109/TMAG.2009.2033352 coercive field related to the formation of single nanocrystalline $\alpha-(\mathrm{Ni}, \mathrm{Fe})$ or $\gamma-(\mathrm{Ni}, \mathrm{Fe})$ phases, which are combined at higher annealing temperatures with the tetragonal $\mathrm{Fe}-\mathrm{B}$ phases bringing strong magneto-crystalline anisotropy that markedly detracts the magnetic softness [6], [7]. On the other hand, the surface properties of Ni-enriched alloys stay completely unexplored. Motivation for this paper is, therefore, twofold. (i) Study of surface crystallization process originating already in as-quenched (AQ) state of FeNiMoCuB ribbons and (ii) comparison their surface magnetic properties with primary FeMoCuB alloys.

\section{EXPERIMENTAL}

AQ nanoperm-type $\mathrm{Fe}_{40} \mathrm{Ni}_{36} \mathrm{Mo}_{8} \mathrm{Cu}_{1} \mathrm{~B}_{15}$ alloy was prepared by planar flow-casting method in a form of ribbons, approximately $20 \mu \mathrm{m}$ thick and $5 \mathrm{~mm}$ wide. However, various experimental methods used for material characterization require different sample lengths.

The microstructure of approximately $2 \mathrm{~cm}$ long sample from the air and wheel ribbon side was scanned by X-ray diffraction (XRD) using CoK $\alpha$ radiation $(\lambda=0.17902 \mathrm{~nm})$ in Bragg-Brentano geometry, detecting the area from depth about $10 \mu \mathrm{m}$. To improve the surface sensitivity of incident X-rays the in-plane diffraction is used as well. Because the beam is incident at a grazing angle, the penetration depth of the beam is limited to within about $100 \mathrm{~nm}$ of the surface (GIXRD). The morphology and the surface roughness were also observed using a Jeol JSM 6460 Scanning Electron Microscope operated at $20 \mathrm{kV}$.

${ }^{57} \mathrm{Fe}$ Mössbauer spectra of $2 \mathrm{~cm}$ long ribbons were measured at room temperature (RT) in scattering geometry by detecting $7.3 \mathrm{keV}$ conversion electrons (CEMS) with the penetration depth about $200 \mathrm{~nm}$. As a source the ${ }^{57} \mathrm{Co}(\mathrm{Rh})$ was used. To observe the surface layer, Integral Low-Energy Electron Mössbauer Spectroscopy (ILEEMS) was applied as well. ILEEMS is a variant of Mössbauer spectroscopy in which lowenergy electrons are counted. The majority of these electrons, with energy of about $10 \mathrm{eV}$, are produced by after effects following the decay of the probe nuclei in an extremely thin surface layer (few nanometers) of the absorber [8]. All obtained 

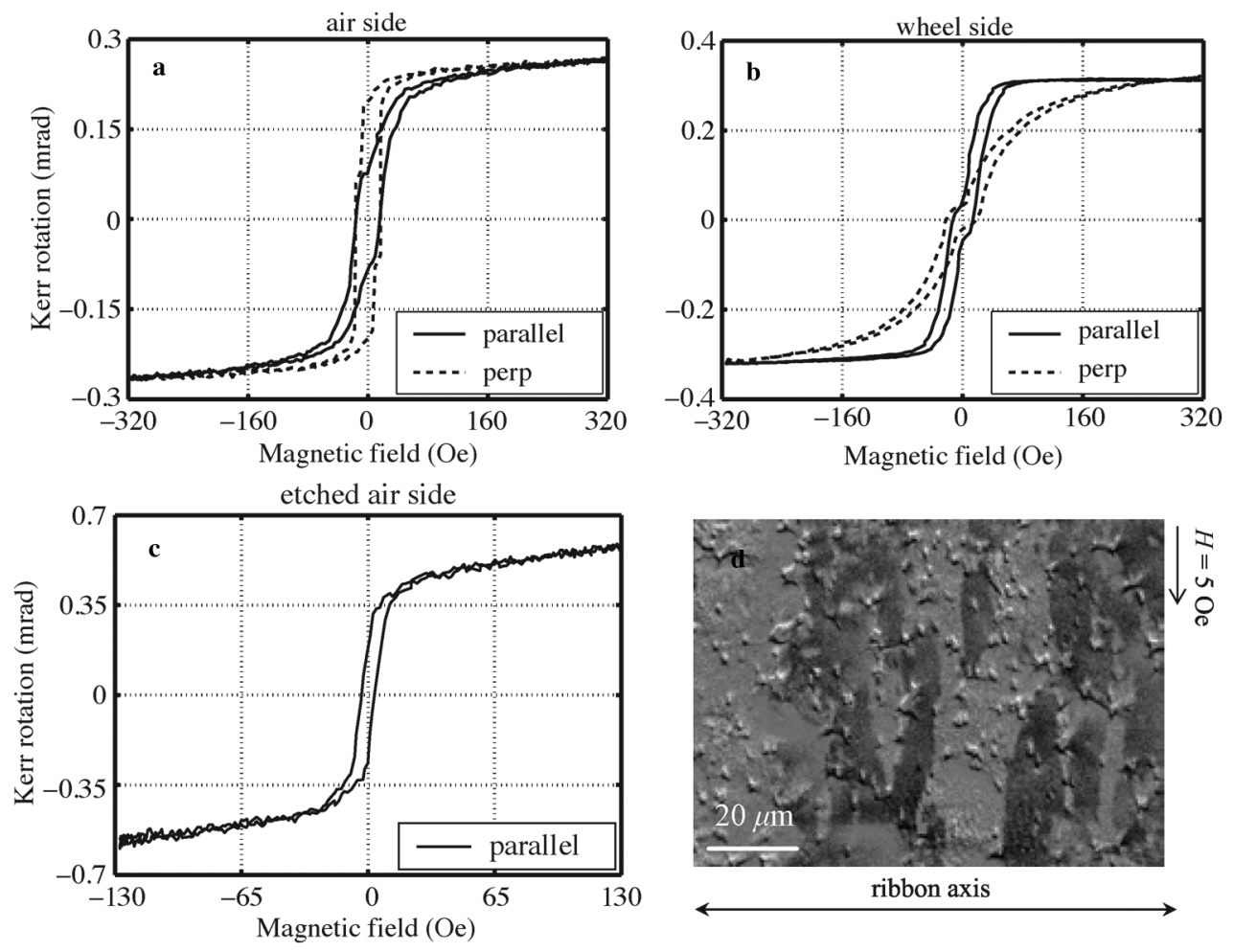

Fig. 1. Measured surface hysteresis loops at air (a), wheel (b), and etched air side (c) of AQ FeNiMoCuB ribbon. Full and dashed lines correspond to experiments, when magnetic field is generated parallel and perpendicular (perp) to the ribbon axis. (d) Domain patterns observed on the shiny surface.

spectra were analyzed using CONFIT program package [9] and calibration of velocity scale is done by a standard thin $\alpha$-iron foil at RT.

The magnetic properties of the near-surface regions were checked by methods based on the magneto-optical Kerr effect (MOKE). Measured MOKE hysteresis loops of Kerr rotations detecting the longitudinal magnetization component in the sample plane and in the plane of incidence are obtained at the incident angle of $60^{\circ}$ in the case of s-polarized incident red light, which penetrates only about a few tens of nm into the material depth. Application of magnetic field parallel and perpendicular to the axis of $5 \mathrm{~mm}$ long square ribbons is suitable for magnetic anisotropy investigations. Moreover, the hysteresis loop measurements are followed by the surface magnetic domains observations using the MO microscopy.

\section{RESULTS AND DISCUSSIONS}

Surface hysteresis loops measured using MOKE from both ribbon sides are shown in Figs. 1(a), (b). Both kinds of experiments, when external magnetic field is generated parallel (solid lines) and perpendicular (perp-dashed lines) to the ribbon axis, reveal double-switch hysteresis loops that, in accordance with the results of XRD and CEMS presented in next paragraphs, correspond to the switching of magnetically harder nanocrystals (coercive field $H_{c 1}$ ) embedded in the softer amorphous matrix with $H_{c 2}$. Values of $H_{c 2}$ slightly differ at both sides moving around $7 \mathrm{Oe}$, while $13 \mathrm{Oe}$ and $16 \mathrm{Oe}$ corresponding to $H_{c 1}$ were measured at wheel and air side in parallel configuration. Rotations of the sample by $90^{\circ}$ (perp configuration) causes not only a
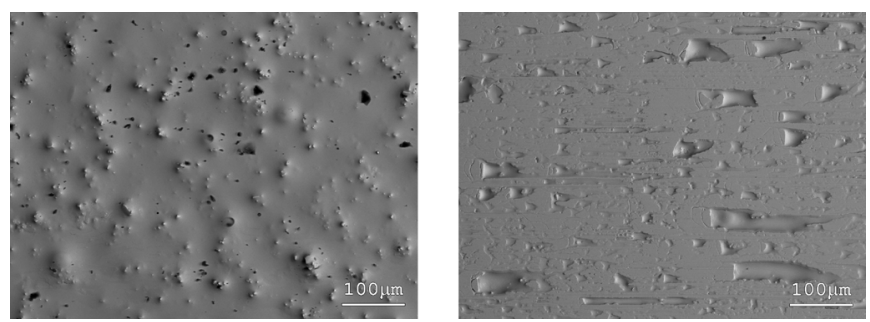

Fig. 2. Morphology of the air (left) and wheel (right) sides of the FeNiMoCuB ribbon sample.

little increase of $H_{c 1}$ values, but strongly influences also the remanent magnetization $M_{R}$ of the curves. Steep increase in $M_{R}$ on the air side indicates the direction of easy magnetization axis perpendicular to the ribbon. Conversely, dashed loop obtained on the wheel side detects harder magnetization axis.

Magnetic anisotropy behavior is also visible from the domains patterns observed on the air ribbon side, see Fig. 1(d). Nearly strip domains captured at small magnetic field in the longitudinal configuration indicate, similar as shapes of the hysteresis loops, the easier magnetization axis perpendicular to the ribbon. The ribbon roughness visible from the domain picture and from the SCAN observation in Figs. 1(d) and 2, respectively, becomes at both sides approximately one order lower in comparison to the original $\mathrm{FeMoCuB}$ ribbons. Unfortunately, grid structure of the surface caused by the quenching wheel and higher roughness due to air pockets (right subplot of Fig. 2) exclude the domains observations on the wheel side.

The fact, that the crystalline phases penetrate much deeper into the material depth then in FeMoCuB alloys, was confirmed 


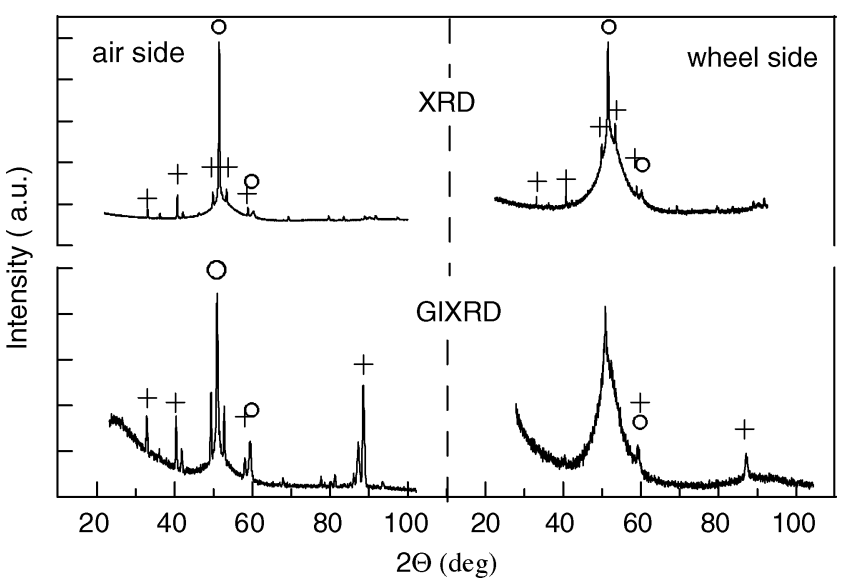

Fig. 3. X-ray diffraction spectra of the AQ FeNiMoCuB sample measured from the air and wheel sides.

by etching of the ribbon surface in concentrated $\mathrm{HNO}_{3}$ acid. In connection with these experiments we found out that ribbon surfaces exhibit relatively high corrosion resistance. Extinction of double-switched hysteresis loops and decrease in the coercive field towards the $H_{c 2}$ (see Fig. 1(c)) is observed after $6 \mathrm{~s}$ of etching procedure. The weight of the ribbon established before and after etching is recalculated for the depth of removed surface and roughly estimates the thickness of the crystalline phase to 8 $\mu \mathrm{m}$ from each side.

The XRD and GIXRD diffraction patterns are depicted in Fig. 3. They clearly show a presence of the sharp crystalline peaks superimposed on broad amorphous halo. The peaks, better resolved in GIXRD patterns, correspond with the $\mathrm{FeMo}_{2} \mathrm{~B}_{2}$, detected also in near-surface regions of original FeMoCuB ribbons, and additional $\mathrm{Fe}_{64} \mathrm{Ni}_{36}$ phases, denoted by "+" and "o" in Fig. 3. The stage of crystallization is more outstanding at the air side (Fig. 3 left). A row estimation of a content of crystalline phase based on line profile analysis gives $32 \%$ for air side and $16 \%$ for wheel side of the ribbon sample. A size of nanocrystals determined using the Scherrer equation [10] ranges between $25 \mathrm{~nm}$ up to $85 \mathrm{~nm}$.

Mössbauer spectroscopy supplies complementary information on the structure of the samples. The CEMS and ILEEMS spectra taken from the wheel side of a ribbon are summarized in Fig. 4. The six broad lines spectra, characteristic of a highly disordered magnetic phase, were analyzed by two distributions of hyperfine inductions based on model of an amorphous structure formed by short-range ordered regions (clusters). The $\mathrm{Fe}$ and $\mathrm{Ni}$ rich clusters are represented by high-field component $\mathrm{C}_{\mathrm{hf}}$ and the clusters with prevailing non-magnetic atoms by low-field component $\mathrm{C}_{\mathrm{lf}}$. Moreover, the double line component detected approximately in the middle of CEMS and ILEEMS spectra of the sample in the AQ state (Fig. 4(a), (b)) corresponds to the paramagnetic (denoted paramag in Table I) component, the content of which in the CEMS spectrum is approximately $3 \%$, while in the ILEEMS 7\%. All hyperfine parameters obtained from measured spectra analysis are summarized in Table I.

As can be seen, there is no important difference in the hyperfine parameters between CEMS and ILEEMS results in the AQ state of sample except the $R_{21}$ parameter. While the magnetic moments prefer random orientation at the surface (ILEEMS),

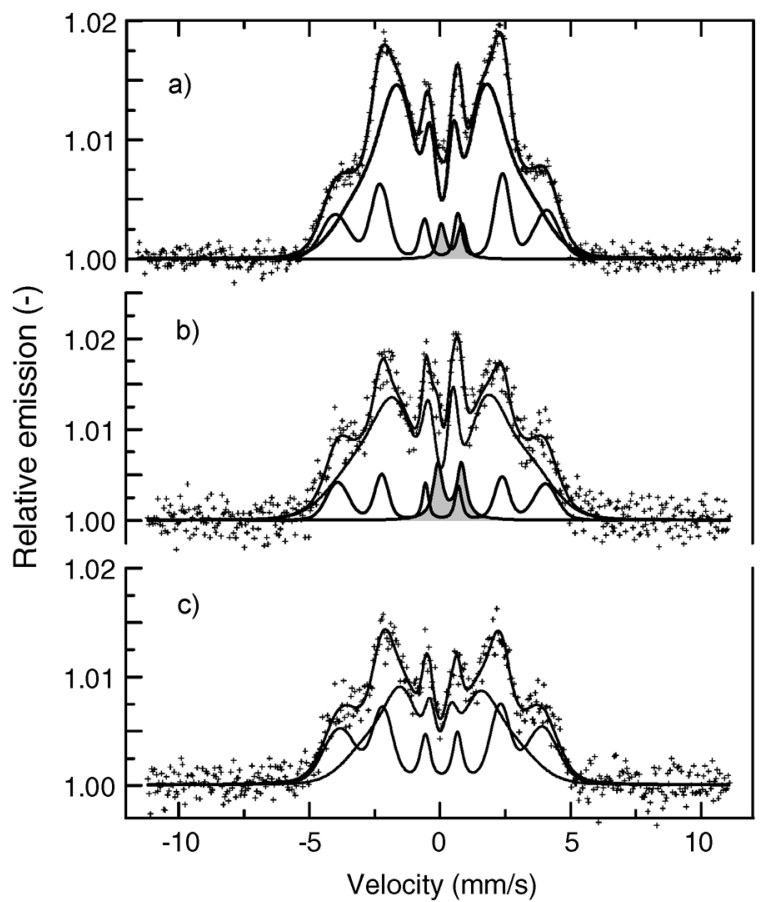

Fig. 4. CEMS (a) and ILEEMS (b), (c) spectra from the wheel side of the FeNiMoCuB sample in the as prepared (AQ) state (a), (b) and after surface etching (c).

the $\mathrm{R}_{21}=1.14$ (CEMS) reflects the orientation of magnetic moments in the ribbon plane, so perpendicular to the $\gamma$-rays. The phase $\mathrm{Fe}_{64} \mathrm{Ni}_{36}$, visible in the diffraction patterns, is ferromagnetic with the hyperfine induction of approx. $25 \mathrm{~T}$ [11] close to mean value of hyperfine induction of the $\mathrm{C}_{\mathrm{hf}}$. Its Mössbauer spectrum is overlapped by broadened spectrum of amorphous phase. Similarly a spectrum of the $\mathrm{FeMo}_{2} \mathrm{~B}_{2}$ is "hidden" in the spectrum of the amorphous phase. The paramagnetic doublet could represent some type of $\mathrm{Fe}(\mathrm{Ni}, \mathrm{Mo})$ oxide, but its more precise identification is not possible from present investigations.

The etching of the sample in the solution of $100 \mathrm{ml} \mathrm{H}_{2} \mathrm{O}$ and $10 \mathrm{ml} \mathrm{HNO}_{3}$ for $4 \mathrm{~h}$ has fully removed the paramagnetic phase as confirmed by ILEEMS measurement in Fig. 4(c). Moreover, a substantial increase in $\mathrm{C}_{\mathrm{hf}}$ component (approximately 2.5 times in comparison to AQ samples) and corresponding decrease in $\mathrm{C}_{\text {lf }}$ component (about 1.4 times) were observed.

The values of the hyperfine parameters presented in Table I for wheel side did not significantly change on the air side. The main observed difference is in the relative representation of paramagnetic component, which increased to 16\% (CEMS). This findings indirectly supports assumption that paramagnetic component represents the oxide phase. The higher tendency to oxidation and/or higher corrosion rate embodies very often the wheel side of ribbons as a consequence of its larger roughness. On the other hand a higher degree of the surface crystallization causes higher oxidation susceptibility in comparison with the amorphous phase [12].

\section{CONCLUSIONS}

The existence of ferromagnetic $\mathrm{FeMo}_{2} \mathrm{~B}_{2}$ and $\mathrm{Fe}_{64} \mathrm{Ni}_{36}$ crystalline phases in the near-surface region of the as-prepared $\mathrm{Fe}_{40} \mathrm{Ni}_{36} \mathrm{Mos}_{8} \mathrm{Cu}_{1} \mathrm{~B}_{15}$ alloy was observed at the air and wheel 
TABLE I

Hyperfine Parameters Obtained From the ANalysis of CEMS and ILEEMS SPeCtra of the FeNiMoCuB SAMPLE ON the WheEl Side: $\mathrm{B}_{\mathrm{m}}$-MeAn HYPERFINE INDUCTION, $\Delta$ B-FWHM (WIDTH OF GAUSSIAN DisTRIBUTION), $\delta$-ISOMER SHIFT, $2 \varepsilon$ Q-QUADRUPOLE SHIFT, $\Delta$ EQ-QUADRUPOLE SPLITTING, A-REL. REPRESENTATION OF COMPONENT, $\mathrm{R}_{21}=\mathrm{I}_{2} / \mathrm{I}_{1}$; I-LINE INTENSITY

\begin{tabular}{|c|c|c|c|c|}
\hline \multirow{2}{*}{ Comp } & \multirow{2}{*}{ Hyperfine parameters } & \multirow{2}{*}{ CEMS } & \multicolumn{2}{|c|}{ ILEEMS } \\
\hline & & & $\mathrm{AQ}$ & etched \\
\hline $\begin{array}{c}\mathrm{C}_{\mathrm{hf}} \\
\text { ferromag. }\end{array}$ & $\begin{array}{c}\mathrm{B}_{\mathrm{m}}[\mathrm{T}] \\
\Delta \mathrm{B}[\mathrm{T}] \\
\delta[\mathrm{mm} / \mathrm{s}] \\
2 \varepsilon \mathrm{Q}[\mathrm{mm} / \mathrm{s}] \\
\mathrm{A}[\%] \\
\mathrm{R}_{21} \\
\end{array}$ & $\begin{array}{c}25.2 \\
6.6 \\
0.041 \\
-0.007 \\
23 \\
1.14 \\
\end{array}$ & $\begin{array}{c}24.8 \\
5.6 \\
0.064 \\
-0.009 \\
17 \\
0.795 \\
\end{array}$ & $\begin{array}{c}24.2 \\
7.7 \\
0.045 \\
-0.015 \\
44 \\
0.927 \\
\end{array}$ \\
\hline $\begin{array}{l}\mathrm{C}_{\mathrm{lf}} \\
\text { ferromag. }\end{array}$ & $\begin{array}{c}\mathrm{B}_{\mathrm{m}}[\mathrm{T}] \\
\Delta \mathrm{B}[\mathrm{T}] \\
\delta[\mathrm{mm} / \mathrm{s}] \\
2 \varepsilon \mathrm{Q}[\mathrm{mm} / \mathrm{s}] \\
\mathrm{A}[\%] \\
\mathrm{R}_{21} \\
\end{array}$ & $\begin{array}{c}17.4 \\
14.8 \\
0.087 \\
0.026 \\
74 \\
1.14 \\
\end{array}$ & $\begin{array}{c}18.1 \\
16.3 \\
0.05 \\
0.038 \\
76 \\
0.795 \\
\end{array}$ & $\begin{array}{c}15.3 \\
13.8 \\
0.01 \\
-0.003 \\
56 \\
0.927 \\
\end{array}$ \\
\hline $\begin{array}{c}\mathrm{C} \\
\text { paramag. }\end{array}$ & $\begin{array}{c}\delta[\mathrm{mm} / \mathrm{s}] \\
\Delta \mathrm{EQ}[\mathrm{mm} / \mathrm{s}] \\
\text { A }[\%]\end{array}$ & $\begin{array}{c}0.443 \\
0.782 \\
3\end{array}$ & $\begin{array}{c}0.373 \\
0.892 \\
7\end{array}$ & \\
\hline
\end{tabular}

side by various surface-sensitive experimental methods. Experiments with the etching of ribbon surface have proved that both phases penetrate deeper into the sample volume. When compared to the primary $\mathrm{FeMoCuB}$ alloys, the following properties were detected by adding the Ni element:

(i) Reduction of the surface roughness at both sides of ribbon and higher resistance against corrosion.

(ii) The increase in coercive field from 4 Oe to $7 \mathrm{Oe}\left(H_{c 2}\right)$, respectively, of amorphous phases in both alloys.

(iii) Existence of both $\mathrm{FeMo}_{2} \mathrm{~B}_{2}$ and $\mathrm{FeNi}$ crystalline phases on the FeNiMoCuB ribbon surface causes marked decrease of coercive field $\left(H_{c 1} \approx 13 \div 16 \mathrm{Oe}\right)$ in comparison to the value of $65 \mathrm{Oe}$ measured for FeMoCuB ribbons.

\section{ACKNOWLEDGMENT}

The authors would like to thank Dr. D. Janičkovič (IP, SAS Bratislava, SK) for supplying the samples and Dr. R. Kužel (CHU Prague) for GIXRD measurements. This work was supported in part by Grants KAN 400100653, MSM6198910016, RMTVC, 1M6198959201 (Ministry of Education, Youth and Sports of the Czech Republic) and Grant AV0Z20410507 (IPM Research Plan). One author, V.G. de Resende, thanks the Fund for Scientific Research-Flanders, and the Special Research Fund (BOF, Bijzonder Onderzoeksfonds), Belgium.

\section{REFERENCES}

[1] C. F. Conde, J. S. Blázquez, V. Franco, A. Conde, P. Švec, and D. Janičkovič, "Microstructure and magnetic properties of FeMoBCu alloys: Influence of B content," Acta Materialia, vol. 55, pp. 5675-5683, 2007.

[2] V. Franco, C. F. Conde, J. S. Blázquez, A. Conde, P. Švec, D. Janičkovič, and L. F. Kiss, "A constant magnetocaloric response in FeMoCuB amorphous alloys with different Fe/B ratios," J. Appl. Phys., vol. 101, p. 093903, 2007.

[3] Y. Jirásková, M. Maryško, and R. Zbořil, "Magnetic and structural features of amorphous FeMo-based alloys," J. Magn. Magn. Mater., vol. 316, pp. e16-e19, 2007.

[4] M. Paluga, P. Švec, D. Janičkovič, P. Mrafko, and C. F. Conde, "Surface morphology in amorphous Fe-Mo-Cu-B ribbon system," J. NonCryst. Solids, vol. 353, pp. 2039-2044, 2007.

[5] M. Paluga, P. Svvec, D. Janičkovič, P. Mrafko, and M. Miglierini, "Surface and volume effects in rapidly quenched Fe-Mo-Cu-B system," $J$. Phys.: Conf. Series, vol. 144, p. 012108, 2009.

[6] P. Butvin, B. Butvinová, E. Illeková, and G. Vlasák, "Macroscopic heterogeneity effects in FeNiNbCuBSi ribbons," J. Magn. Magn. Mater., vol. 237, pp. L237-L240, 2001.

[7] K. Y. He, Y. H. Zhao, G. G. Li, L. Z. Cheng, B. Wu, M. L. Sui, and W. Z. Chen, "Studies of crystallization and soft magnetic properties of FeNiMoB(Si) alloys," J. Magn. Magn. Mater., vol. 316, pp. 34-39, 2007.

[8] E. De Grave, R. E. Vandenberghe, and C. Dauwe, "ILEEMS: Methodology and applications to iron oxides," Hyperfine Interact., vol. 161, pp. 147-160, 2005.

[9] T. Zak and Y. Jiraskova, "CONFIT: Mössbauer spectra fitting program,” Surf. Interf. Anal., vol. 38, pp. 710-714, 2006.

[10] A. Guinier, X-Ray Diffraction, In Crystals, Imperfect Crystals, and Amorphous Bodies. New York: Dover, 1994, p. 121.

[11] , H. P. J. Wijn, Ed., Magnetic Properties of Metals, d-Elements, Alloys and Compounds. Berlin Heidelberg, Germany: Springer-Verlag, 1991, p. 27.

[12] N. A. Mariano, C. A. C. Souza, M. F. Oliveira, and S. E. Kuri, "Enhanced corrosion resistance of amorphous and nanocrystalline FeNbB alloys," Mater. Sci. Forum, vol. 343-346, pp. 861-866, 2000. 